details will be familiar to those who have studied the effects of contact between primitive and Western culture and the irreparable disasters which have followed upon such contacts in the last hundred years.

Is putting forward certain suggestions as to how best to deal with the situation in areas in which the natives are at present virtually untouched, such as parts of New Guinea, the islands of New Britain, and the Congo, two principles are enunciated, one ethical, namely, that the ruling power must not restrict the natives' opportunities of ordered cultural development, the second that in the interests of science opportunity should be preserved for study of native cultures before they are hopelessly corrupted by unregulated contact with the worse elements in Western civilization. Accepting the view that the interests of the native should be the first consideration, since commerce and industry may be trusted to look after themselves, the committee suggests that reserves should be created, not for the preservation of native tribes and cultures as museum pieces, but in order that these backward peoples may be led to develop gradually under supervision and strict regulation of contacts, cultural and other, in a slow but healthy upward progression, in which the elements of their own culture will be assimilated in higher forms of eivilization. It will be seen that the ideal formulated by the Dutch Committee is sufficiently in accord with the views of those in Great Britain, who press for a scientific approach to the problem of the future of backward peoples, to warrant co-operation in the attainment of what is the common end. In any event, they will agree with the committee that the problem is urgent and immediate.

\section{Jubilee of the American Mathematical Society}

THE fiftieth anniversary of the founding of the American Mathematical Society, which is being celebrated early in September at Columbia University, New York City, in connexion with the annual summer meeting of the Society, is unusual among jubilees of learned societies in that the principal founder of the organization in 1888 is serving as chairman of the committee in charge of the jubilee celebrations. Prof. Thomas Scott Fiske, now emeritus professor of mathematics in Columbia University, took the initiative in bringing together six mathematicians fifty years ago to establish the New York Mathematical Society, having received his inspiration to do this from his attendance at meetings of the London Mathematical Society while a student at Cambridge the preceding year. Dr. Fiske, as secretary of the young society, was indefatigable in his efforts to increase its membership, and succeeded so well that in 1891 the Society was strong enough to begin publication of the Bulletin of the New York Mathematical Society, which has been continued to the present time as the official organ of the Society, its name, of course, having been changed to correspond to the change in name of the Society to American Mathematical Society in 1894.

IN 1900, the journal entitled Transactions of the American Mathematical Society was established by the Society for the publication of research papers. In the course of time the service of the Society to its membership in the promotion of mathematical research has come to include also an annual course of lectures on recent advances in some specific field of mathematics, and the publication of these in a series of Colloquium Publications, now numbering twenty-four volumes, the Josiah Willard Gibbs lectureship on applied mathematics, the maintenance of a library especially strong in relatively obscure journals, the award from time to time of several endowed prizes and the holding of ten or more meetings annually for the communication of approximately five hundred research papers. For many years Columbia University has provided office space for the Society, and more than half the regular meetings of the Society have been held in the University.

\section{The Centro Volpi di Elettrologia}

Count Voupr di Misurata, whose name is associated with many important Italian electric companies, has decided, in the interests of science, to create an institution in Italy to promote the knowledge of, and research in, electrical science. He has presented the magnificent Vendramin-Calergi Palace in Venice to serve as a home for the new institution which will be known as the Centro Volpi di Elettrologia after its founder. It is so arranged that it works in harmony with other existing Italian scientific societies. Its principal object is the improvement of electrical knowledge by means of new cultural exchanges between Italian and foreign scientists. Its main activities will be to publish a bulletin giving summaries of recent Italian researches, translated into various languages in different editions for distribution abroad. It will also promote international congresses and meetings of men of science in the quiet Venetian palace so that they may advance electrical knowledge by exchanging ideas on specific scientific questions.

WE have received a copy of the first bulletin of the Centro Volpi di Elettrologia in English. It illustrates briefly the activities of and the schemes initiated by the Centro Volpi. It reports in the form of short abstracts all Italian publications dealing with electrical subjects. Great pains have been taken with the documentation of the bulletin. Each abstract is of such a size that it can be cut and gummed on an international card in accordance with the resolutions and recommendations of the World Congress of Documentation. Later on, should some article appear which is important either on account of new ideas or results, or because it serves as a basis for cultural exchanges, an amplified summary will be given in addition to the usual notice. In this bulletin an interesting article on "Acoustical Research in Italy" is given. The plans and sections of the new acoustic laboratory in the national electrotechnical institute 'G. Ferraris' in Turin is described. At present the laboratory has in use four reverberating rooms and two sound-absorbing rooms. When completed it will have a sound-proof room for microphonic calibrations and acoustimetric experiments. 